\title{
Undiagnosed Cryptococcus gattii meningitis leading to subsequent ventriculoperitoneal shunt infection in a patient with symptoms of normal pressure hydrocephalus: case report and literature review
}

\author{
Wutthiseth Dhitinanmuang ${ }^{1}$, Piriyaporn Chongtrakool ${ }^{2}$ and Anupop Jitmuang ${ }^{1 *}$
}

\begin{abstract}
Background: Cryptococcus gattii is known to be an etiologic agent of human cryptococcosis, particularly in immunocompetent persons. C. gattii infection usually involves the central nervous system, the respiratory tract, or may be disseminated. Here we report an atypical manifestation of $C$. gattii infection in a patient who had C. gattii meningitis complicating the ventriculoperitoneal (VP) shunt infection and concurrent infected intraabdominal VP shunt pseudocyst.

Case presentation: A 66-year-old Thai female was initially diagnosed with normal pressure hydrocephalus (NPH) and underwent programmable VP shunt placement. However, she still suffered from recurrent communicating hydrocephalus with in-place VP shunt, and later developed recurrent gait impairment, chronic abdominal pain and abdominal mass. Radiological studies demonstrated recurrent hydrocephalus and a very large intraabdominal VP shunt pseudocyst. C. gattii was isolated from both the cerebrospinal fluid and the pseudocyst aspiration. C. gattii meningitis complicating the VP shunt infection and concurrent infected intraabdominal VP shunt pseudocyst was diagnosed. Prolonged antifungal therapy, removal of the infected VP shunt with subsequent implant of a new shunt provided a good outcome.

Conclusion: Chronic C. gattii meningitis should be aware in a patient presenting with normal pressure hydrocephalus. Under-diagnosed cryptococcal meningitis following VP shunt insertion for treating the hydrocephalus can render a complicated VP shunt infection including infected VP shunt pseudocyst.
\end{abstract}

Keywords: Cryptococcus gattii, Cryptococcal meningitis, Ventriculoperitoneal shunt infection, Infected ventriculoperitoneal shunt pseudocyst

\section{Background}

Cryptococcosis is one of the more common systemic fungal infections caused by two main species, Cryptococcus neoformans and Cryptococcus gattii. Cryptococcus is a spore forming, environmental encapsulated fungus [1, 2]. Formerly, human Cryptococcus had been grouped into 4 major serotypes based on antigenic differences of the polysaccharide

\footnotetext{
* Correspondence: anupopmix@yahoo.co.th

${ }^{1}$ Division of Infectious Diseases and Tropical Medicine, Department of Medicine, Faculty of Medicine Siriraj Hospital, Mahidol University, 2 Wanglang Road, Bangkoknoi, Bangkok 10700, Thailand

Full list of author information is available at the end of the article
}

capsules, namely serotypes A, B, C and D $[1,3]$. C. neoformans was categorized into serotypes $\mathrm{A}$ and $\mathrm{D}$ whereas $C$. gattii was classified into the serotypes B and C. Inhalation of spores is a primary route of infection that mainly affects immunocompromised persons, such as HIV-infected patients, organ transplant recipients, and patients receiving corticosteroid or immunosuppressive agents. However, several published reports have demonstrated C. gattii to be frequently associated with cryptococcosis in patients with no known immunodeficiency [4-6].

(c) The Author(s). 2018 Open Access This article is distributed under the terms of the Creative Commons Attribution 4.0 International License (http://creativecommons.org/licenses/by/4.0/), which permits unrestricted use, distribution, and 
In recent years, the prevalence of $C$. gattii infection has increased since a major outbreak on Vancouver Island [4]. Similar to C. neoformans, central nervous system (CNS) and respiratory tract infections are the most common presentations [1-4]. However, C. gattii infection occurs more frequently in immunocompetent persons and more often results in CNS complications, such as hydrocephalus, and large cryptococcoma with delayed treatment response $[1,2,7]$. Few studies of C. gattii infection in Thailand have been published. A molecular typing study of 498 Cryptococcus spp. isolates from clinical, animal and environmental sources from Thailand found only 13 isolates (2.6\%) were C. gattii, but clinical data have not been reported [3]. Another study described Tsunami survivors from Thailand who suffered from primary cutaneous cryptococcosis caused by $C$. gattii [5]. Here we report atypical C. gattii infection in a patient who had chronic C. gattii meningitis complicating a ventriculoperitoneal (VP) shunt infection and concurrent infected intraabdominal VP shunt pseudocyst.

\section{Case presentation}

A 66-year-old Thai female with underlying hypertension was admitted to Siriraj Hospital, Bangkok, Thailand on September 26, 2016 to evaluate the function of an implanted VP shunt and identify the cause of an abdominal mass. Two years earlier, she had progressive memory impairment, dizziness, and difficulty walking for 4 months. Computed tomography (CT) of the brain revealed communicating hydrocephalus without leptomeningeal enhancement or abnormal enhancing lesion. Initial cerebrospinal fluid (CSF) showed a white blood cell (WBC) count of 54 cells $/ \mathrm{mm}^{3}$ with $96 \%$ lymphocytes, a protein $165 \mathrm{mg} / \mathrm{dL}$, and a ratio of CSF/serum glucose of $25 / 126 \mathrm{mg} / \mathrm{dL}(0.2)$. The patient was diagnosed with normal pressure hydrocephalus (NPH) and underwent programmable VP shunt placement to relieve her symptoms. One year later, the gait difficulty and dizziness resumed. A brain $\mathrm{CT}$ showed recurrent communicating hydrocephalus. The neurological deficits were reduced after adjusting the VP shunt pressure. Six months following adjustment of the shunt pressure, the patient developed abdominal discomfort with a palpable mass at the right paraumbilical region. The patient did not feel feverish and did not have nausea or vomiting. Prior to this admission, gait difficulty and dizziness including diffuse headache recurred. Recurrent hydrocephalus was suspected and the patient was admitted for further investigation.

The patient was afebrile and had a very large, ill-defined mass with cystic consistency and smooth surface at the right paraumbilical region. Neurological examination revealed a magnetic gait, no neck stiffness and otherwise normal findings. The brain $\mathrm{CT}$ revealed communicating hydrocephalus with appropriate in-place VP shunt as shown in Fig. 1a. The abdominal CT identified a well-defined rounded cystic mass measuring approximately $9.6 \times 11.3 \times 15 \mathrm{~cm}$ at the inframesocolic space. This cystic mass encased the distal end of the VP shunt, suggestive of a CSF pseudocyst (Fig. 1b). CSF was collected by lumbar puncture and returned a WBC count of 12 cells $/ \mathrm{mm}^{3}$ with $94 \%$ lymphocytes, $20 \mathrm{mg} / \mathrm{dL}$ protein, and a ratio of CSF/serum glucose of 46/106 mg/ $\mathrm{dL}$ (0.43). Ultrasonography-guided aspiration of the intraabdominal VP shunt pseudocyst was also performed. A total of $360 \mathrm{~mL}$ of clear yellow fluid was obtained and examined. The WBC count was $20 \mathrm{cell} / \mathrm{mm}^{3}$ with $97 \%$ lymphocytes, $472 \mathrm{mg} / \mathrm{dL}$ protein, and a ratio of CSF/serum glucose of $<4.32 / 120 \mathrm{mg} / \mathrm{dL}(<0.03)$. An India ink preparation of the CSF taken from the

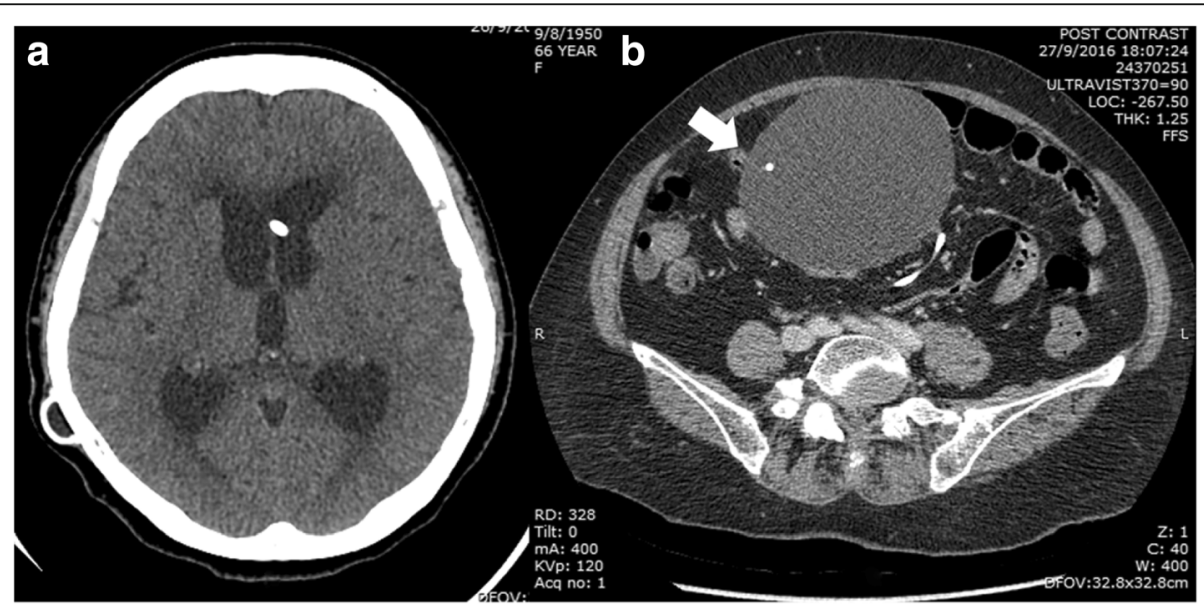

Fig. 1 a) Computed tomography of brain revealed recurrent communicating hydrocephalus with appropriate in-place VP shunt, b) Computed tomography of whole abdomen with contrast revealed a large well-defined cystic mass at inframesocolic space, approximately $9.6 \times 11.3 \times 15 \mathrm{~cm}$ in diameter which it encased the distal limb of VP shunt (arrow) 
pseudocyst and from the lumbar puncture revealed a few encapsulated budding yeasts. Cryptococcal antigen testing of the serum and the CSF was positive at the titers of $1: 8$ and of $>1: 1024$, respectively. The yeasts grew well on saboraud dextrose agar without cycloheximide. The isolate was identified as $C$. gattii by biochemical testing and a conversion to blue color on L-canavanine-glycine bromothymol blue (CGB) agar. A molecular typing using the restriction fragment length polymorphism (RFLP) of URA5 determined the isolate to be compatible with C. gattii molecular type VGI. Antifungal susceptibility testing by the broth microdilution method was performed and showed minimal inhibitory concentrations (MICs) of amphotericin B deoxycholate (ABD) of $0.5 \mu \mathrm{g} / \mathrm{mL}$, 5-fluorocytosine (5-FC) of $0.5 \mu \mathrm{g} /$ $\mathrm{mL}$, fluconazole of $1 \mu \mathrm{g} / \mathrm{mL}$, itraconazole of $\leq 0.015 \mu \mathrm{g} /$ $\mathrm{mL}$, voriconazole of $0.015 \mu \mathrm{g} / \mathrm{mL}$, posaconazole of $0.03 \mu \mathrm{g} / \mathrm{mL}$ and all echinocandins (caspofungin, micafungin and anidulafungin) of $>8 \mu \mathrm{g} / \mathrm{mL}$. Unfortunately, when NPH was initially diagnosed 2 yrs earlier the CSF culture had grown C. gattii, but the result was overlooked. Chest radiography found no pulmonary nodules or infiltrations. Complete blood count showed hemoglobin of $12.4 \mathrm{~g} / \mathrm{dL}$, hematocrit of $39.4 \%$, WBC counts of $10,930 / \mathrm{mm}^{3}$ (neutrophil $70 \%$, lymphocyte $25 \%$, monocyte $5 \%$ ) and platelet counts of $385,000 / \mathrm{mm}^{3}$. Blood urea nitrogen (BUN), creatinine, and liver function tests were within normal limits. Anti-HIV testing was negative. Immunological studies revealed $\mathrm{CD}_{4} \mathrm{~T}$ cell counts of 842 cells $/ \mathrm{mm}^{3}$ (51.8\%), $\mathrm{CD}_{8} \mathrm{~T}$ cell counts of 361 cells $/ \mathrm{mm}^{3}$ (22.2\%), IgG $1170 \mathrm{mg} / \mathrm{dL}$, IgA $255 \mathrm{mg} / \mathrm{dL}$ and IgM $141 \mathrm{mg} / \mathrm{dL}$. Anti-interferon gamma (anti-IFN- ) and anti-granulocyte-macrophage colony-stimulating factor (anti-GM-CSF) autoantibodies were both negative.

During hospitalization, the patient received daily intravenous amphotericin B deoxycholate $40 \mathrm{mg}(0.7 \mathrm{mg} / \mathrm{kg} /$ day) combined with oral fluconazole $800 \mathrm{mg} /$ day. The VP shunt was removed after 14 days of antifungal treatment. After discharge to home, the patient received long-term oral fluconazole for consolidation and maintenance therapy according to the IDSA recommendation [7]. Reimplantation of the VP shunt was performed after 8 weeks of antifungal treatment. The follow-up CSF culture was sterile. Brain CT following shunt reimplantation demonstrated significantly decreased ventricular dilatation (Fig. 2). After 6 months of antifungal treatment, the gait abnormality, dizziness and diffuse headache resolved, and the abdominal mass was no longer detectable.

\section{Discussion}

This patient without apparent immunodeficiency presented with cryptococcal meningitis complicating communicating hydrocephalus similar to other reports $[1,2,4,6,8]$. However, this patient was initially misdiagnosed with normal pressure hydrocephalus requiring VP shunt placement, although the CSF culture completed 2 yrs earlier had revealed the presence of C. gattii infection. Chronic, undiagnosed C. gattii meningitis following the VP shunt placement lead to multiple recurrent communicating hydrocephalus, and eventually resulted in a cryptococcal intraabdominal VP shunt pseudocyst. A summary of nine case reports of cryptococcal VP shunt infection including the present case is provided in Table 1 [9-14]. Only three patients had immunodeficient conditions such as HIV infection (2) and diabetes mellitus with liver cirrhosis (1), while the six cases left had no apparent immunodeficient states. Previous studies tentatively found an association among human leucocyte antigen (HLA) subtypes and fungal infections such as histoplasmosis [15], paracoccidioidomycosis [16]. A study conducted in Papua New Guinea revealed patients conferred HLA B*5601 were likely susceptible to C. gattii infection [17]. However, a relation of HLA and genetic susceptibility to fungal infections is still inconclusive and requires more studies. In Asian population including Thai patients, anti-IFN- autoantibodies have associated with disseminated infection secondary to several opportunistic organisms, such as nontuberculous mycobacteria, Salmonella non-Typhi, Varizella-zoster virus and fungi [18]. In addition, high level of anti-GM-CSF autoantibodies was associated with cryptococcal meningitis $[19,20]$ and disseminated cryptococcosis [21] in HIV-negative patients who had no previously apparent

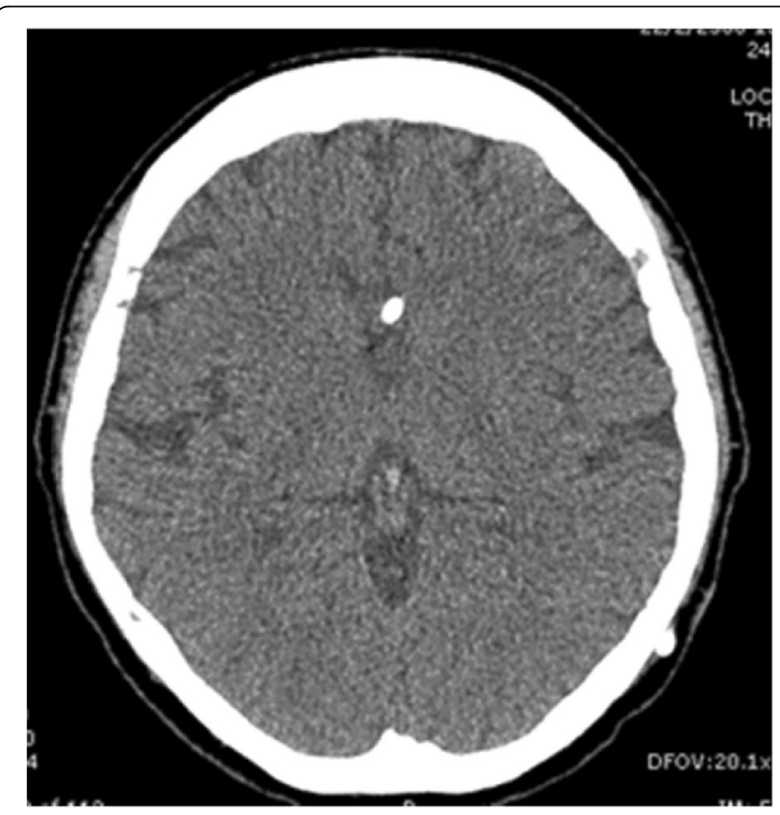

Fig. 2 Computed tomography of brain following the shunt reimplantation exhibited significantly decreased ventricular dilatation 


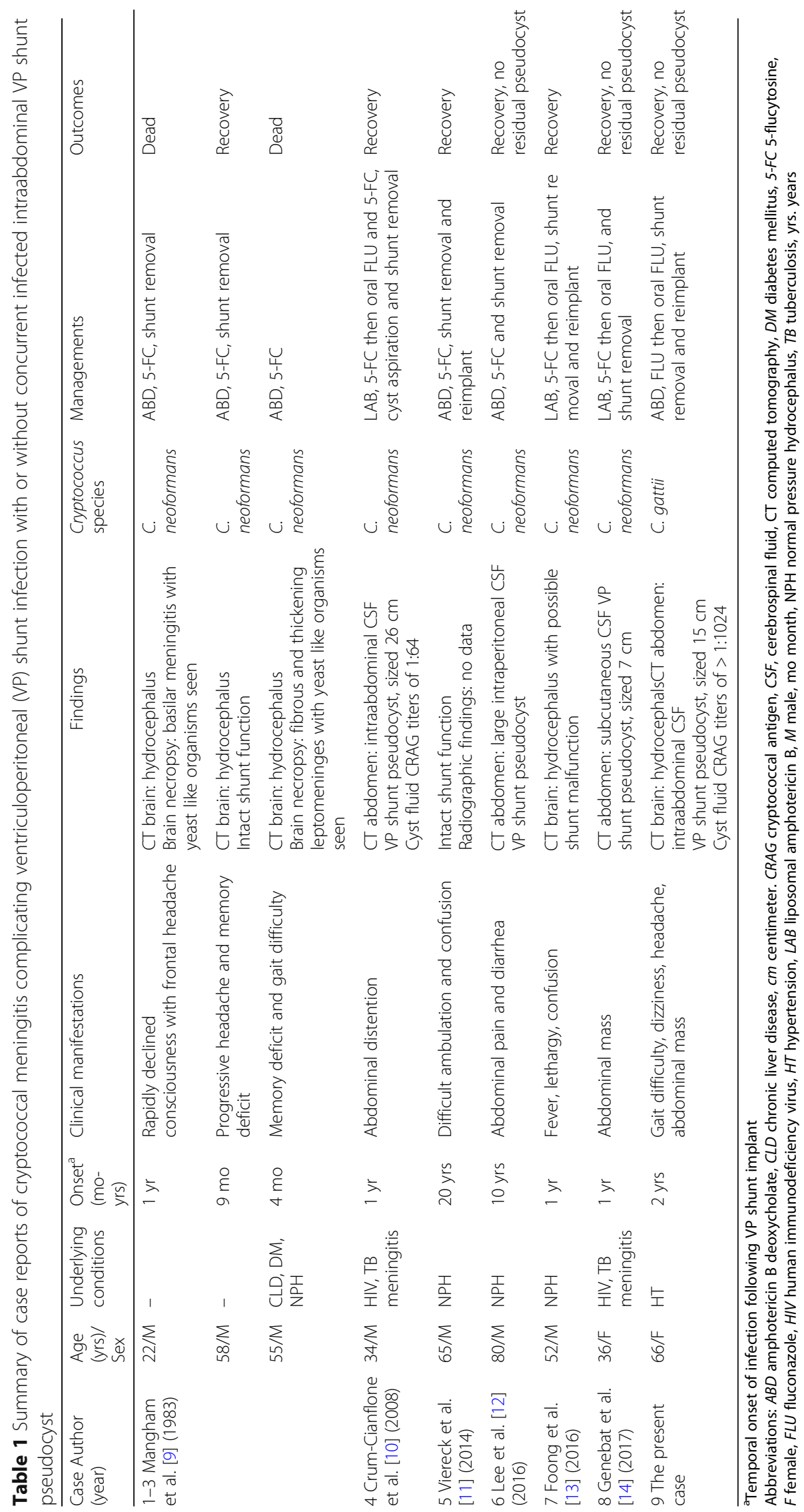


immunodeficiencies. The present case had negative results of the both autoantibodies. Unfortunately, information on the immunological studies of the previous cases in the Table 1 have been unknown. From the Table 1, cryptococcal VP shunt infection may be separated into early onset, within several months to a few years post implant, and late onset more than 10 years post implant. We postulate that an undiagnosed Cryptococcus infection might be the primary cause of neurological deficits in patients who presented with early onset infection. These patients received VP shunt placements to relieve their symptoms, but an occult Cryptococcus infection subsequently causes a shunt infection soon after. Cryptococcus can also cause a sporadic VP shunt infection in patients who had the shunt implant several years earlier. Of nine cases, three also had concurrent infected abdominal pseudocysts and one had a subcutaneous pseudocyst following the VP shunt infections. Clinical manifestations such as abdominal distention, abdominal pain, or abdominal mass were comparable among these patients. The infected pseudocysts were moderate to large in size, and cyst fluid tested for cryptococcal antigens from two patients showed high titers.

The present case is unique for several reasons. First, this patient was initially misdiagnosed as NPH for 2 years. The reasons of slow progression in this patient may be from the released CSF by VP shunt at the onset of NPH, an ability to produce biofilm formation and a variation of virulence based on strain typing. Previous experimental studies elucidated $C$. neoformans exhibited exopolymeric matrices including capsular polysaccharide promoting adherence to VP shunt [22] and plastic surface [23], and was resistant to host immune response causing persistent infection. Second $C$. gattii was the only pathogen isolated from CSF and fluid from the pseudocyst in the present case while $C$. neoformans was the principle etiologic agent in the other cases. Third, intraabdominal VP shunt pseudocyst infection caused by C. gattii has not been previously reported. Molecular typing of the isolate identified C. gattii VGI strain, an uncommon type. According to the molecular typing studies, C. gattii VGII is the most common molecular type distributed in Thailand and other countries [3, 4]. Of 386 Cryptococcus isolates from Thailand, 12 (3.1\%) were $C$. gattii VGII and only $1(0.3 \%)$ was a VGI strain [3]. Interestingly, multi-locus sequence typing (MLST) revealed all but 1 of the C. gattii VGII had an identical linkage to the genotype of Vancouver outbreak strains [3]. Clinical manifestation from each molecular type were not significantly different, but most of the confirmed cases who died had an infection caused by the subtyped VGIIa (67\%) and the subtyped VGIIb (27\%) [4]. Several studies demonstrated that the subtyped VGIIa was more virulent than other strains [2, 24-26].
The present case had a CNS infection caused by the rare VGI strain. The insidious onset and slow progression of the CNS infection we observed might be associated with the less virulent VGI strain. The MICs of antifungal agents, such as ABD, 5-FC and azoles were active against the $C$. gattii isolated from our patient. However, the standard breakpoint of antifungal susceptibility testing for Cryptococcus spp. is still not available. Fluconazole resistance is uncommon among $C$. gattii although increasing fluconazole MICs of C. gattii VGII has been reported [27-29]. Thus, molecular typing and antifungal susceptibility testing may affect treatment outcomes in C. gattii infection.

Most of the case reports received a combination of conventional or liposomal amphotericin with 5-FC, which is the first line antifungal therapy for treating severe cryptococcal infection [7]. In the present case, high dose fluconazole was substituted because 5-FC is restricted use and not widely available in Thailand. Fluconazole is an alternative agent used for combination with amphotericin when treating HIV-infected patients with severe C. neoformans infection [7]. Although amphotericin $B$ in combination with fluconazole showed in vitro antagonistic interaction [30], several clinical studies demonstrated the combined two-drug regimen provided favorable outcomes for treating HIV-infected patients with cryptococcal meningitis where 5-FC was not available or contraindicated [3133] However, clinical studies of cryptococcal meningitis in non-HIV infected individuals have been limited. All cases listed in Table 1 that survived continued the oral fluconazole therapy for several weeks. Following the induction of combined antifungal agents, patients who have cryptococcal infection require long term fluconazole therapy to prevent relapse [7]. Neurological complications such as increased intracranial pressure or hydrocephalus, must be managed by CSF drainage procedures. The present case initially received a VP shunt to reduce hydrocephalus though the first CSF culture was positive for C. gattii at the onset. It is possible that placement of the VP shunt may have prevented a rapid deterioration in neurological status. Of the nine reported cases, eight had the VP shunt removal, and three of these including the present case subsequently had a shunt reimplant. All of these patients had neurological recovery and no recurrence following the reimplantation. Thus, in patients with cryptococcal meningitis complicating VP shunt infection, shunt removal followed by a reimplant is considered safe and provides a good outcome. Four patients who had concurrent infected abdominal pseudocysts required no surgical excision. Simple aspiration of the infected pseudocyst and prolonged antifungal therapy provided a favorable outcome. 


\section{Conclusion}

C. gattii infection should be considered in patients who develop normal pressure hydrocephalus without apparent cause. VP shunt implant is usually performed to relieve neurological deficits. An undiagnosed cryptococcal infection can result in VP shunt infection and infected intraabdominal VP shunt pseudocyst. CSF examination, cryptococcal antigen testing and fungal culture are mandatory to diagnosis this condition. Long term antifungal treatment, removal of the infected shunt followed by reimplantation when appropriate results in a favorable outcome.

\section{Abbreviations}

5-FC: 5-flucytosine; ABD: Amphotericin B deoxycholate; anti-GM-CSF: Antigranulocyte-macrophage colony-stimulating factor; anti-IFN-Y: Antiinterferon gamma; BUN: Blood urea nitrogen; CGB: L-canavanine-glycine bromothymol blue; CNS: Central nervous system; CSF: Cerebrospinal fluid; CT: Computed tomography; HLA: Human leucocyte antigen; Ig: Immunoglobulin; MICs: Minimal inhibitory concentrations; NPH: Normal pressure hydrocephalus; RFLP: Restriction fragment length polymorphism; VP shunt: Ventriculoperitoneal shunt; WBC: White blood cell

\section{Acknowledgements}

The authors would like to acknowledge neurosurgeons at Siriraj Hospital for management of the patient, and the staff of Mycology Laboratory Unit, Department of Microbiology for providing the microbiological data.

\section{Availability of data and materials}

All data and materials of this article are included in the manuscript and thus available to the reader.

\section{Authors' contributions}

WD and AJ carried out the clinical follow up and draft the manuscript. PC supervised mycology laboratory, antifungal susceptibility testing, fungal identification, and molecular typing. All authors read and approved the final manuscript.

\section{Ethics approval and consent to participate}

This case report has been granted an exemption from requiring ethics approval according to the Scientific Ethics Committee of the Siriraj Institutional Review Board (SIRB), Faculty of Medicine Siriraj Hospital, Mahidol University.

\section{Consent for publication}

Written informed consent was obtained from the participating patient for publication of this case report and any accompanying images. A copy of the written consent is available for review upon request.

\section{Competing interests}

The authors declare that they have no competing interests.

\section{Publisher's Note}

Springer Nature remains neutral with regard to jurisdictional claims in published maps and institutional affiliations.

\section{Author details}

'Division of Infectious Diseases and Tropical Medicine, Department of Medicine, Faculty of Medicine Siriraj Hospital, Mahidol University, 2 Wanglang Road, Bangkoknoi, Bangkok 10700, Thailand. 'Department of Microbiology, Faculty of Medicine Siriraj Hospital, Mahidol University, Bangkok, Thailand.
Received: 5 September 2017 Accepted: 25 May 2018

Published online: 04 June 2018

\section{References}

1. Perfect JR. Cryptococcosis (Cryptococcus neoformans and Cryptococcus gattii). In: Bennett JE, Dolin R, Blaser MJ, editors. Mandell, Douglas, and Bennett's principles and practice of infectious diseases. 8th ed. Philadelphia: Elsevier; 2015. p. 2934-48.

2. Chen SC, Meyer W, Sorrell TC. Cryptococcus gattii infections. Clin Microbiol Rev. 2014;27(4):980-1024

3. Kaocharoen $\mathrm{S}$, Ngamskulrungroj P, Firacative C, Trilles L, Piyabongkarn D, Banlunara $W$, et al. Molecular epidemiology reveals genetic diversity amongst isolates of the Cryptococcus neoformans/C. gattii species complex in Thailand. PLoS Negl Trop Dis. 2013;7(7):e2297.

4. Galanis E, MacDougall L. Epidemiology of Cryptococcus gattii, British Columbia, Canada, 1999-2007. Emerg Infect Dis. 2010;16(2):251-7.

5. Leechawengwongs M, Milindankura S, Sathirapongsasuti K, Tangkoskul T, Punyagupta S. Primary cutaneous cryptococcosis caused by Cryptococcus gattii VGIl in a tsunami survivor from Thailand. Med Mycol Case Rep. 2014;6:31-3.

6. Amburky JW, Miller JH, Ditty BJ, Lune PV, Muhammad S, Fisher WS. Cryptococcus gattii in an immunocompetent patient in the southeastern United States. Case Resp Infect Dis. 2016;2016:1-4.

7. Perfect JR, Dismukes WE, Dromer F, Goldman DL, Graybill JR, Hamill RJ, et al. Clinical practice guidelines for the management of cryptococcal disease: 2010 update by the Infectious Diseases Society of America. Clin Infect Dis. 2010;50(3):291-322.

8. Garber ST, Penar PL. Treatment of indolent, non-encapsulated cryptococcal meningitis associated with hydrocephalus. Clin Pract. 2012;2:e22.

9. Mangham D, Gerding DN, Peterson LR, Sarosi GA. Fungal meningitis manifesting as hydrocephalus. Arch Intern Med. 1983;143(4):728-31.

10. Crum-Cianflone N, Truett A, Wallace MR. Cryptococcal meningitis manifesting as a large abdominal cyst in a HIV-infected patient with a CD4 count greater than 400 cells/ $/ \mathrm{mm}^{3}$. AIDS Patient Care STDs. 2008; 22(5):359-63.

11. Viereck MJ, Chalouhi N, Krieger DI, Judy KD. Cryptococcal ventriculoperitoneal shunt infection. J Clin Neurosci. 2014;21(11):2020-1.

12. Lee CH, Liao KH, Lin HY, Lui TN, Ou TY, Lee WS. Cryptococcal meningitis complicated with a large abdominal cyst mimicking acute pancreatitis. J Microbiol Immunol Infect. 2016;49(3):466-7.

13. Foong KS, Lee A, Vasquez G. Cryptococcal infection of the ventriculoperitoneal shunt in an immunocompetent patient. Am J Case Rep. 2016;17:31-4.

14. Genebat M, Maria J, Mayorga-Buiza, Esperanza GO, Monica RG, Francisco J, et al. Cryptococcal infection of the ventriculoperitoneal shunt in an HIVinfected patient with an excellent immunovirologic status. World Neurosurg. 2017;99:810.e11-3.

15. Zimmer A, Miller $G$, Mallal $S$, Thomas L. Human leukocyte antigen and risk of disseminated histoplasmosis in solid organ transplant recipients. Transpl Infect Dis. 2016;18(1):160-1.

16. Sadahiro A, Roque AC, Shikanai-Yasuda MA. Generic human leukocyte antigen class II (DRB1 and DQB1) alleles in patients with paracoccidioidomycosis. Med Mycol. 2007;45(1):35-40.

17. Van Dam MG, Seaton RA, Hamilton AJ. Analysis of HLA association in susceptibility to infection with Cryptococcus neoformans var. gattii in a Papua new Guinean population. Med Mycol. 1998:36:185-8.

18. Browne SK, Burbelo PD, Chetchotisakd P, Suputtamongkol Y, Kiertiburanakul $\mathrm{S}$, Shaw PA, et al. Adult-onset immunodeficiency in Thailand and Taiwan. N Engl J Med. 2012;367(8):725-34.

19. Saijo T, Chen J, Chen SC, Rosen LB, Yi J, Sorrell TC, et al. Anti-granulocytemacrophage colony-stimulating factor autoantibodies are a risk factor for central nervous system infection by Cryptococcus gattii in otherwise immunocompetent patients. MBio. 2014;5(2):e00912-4.

20. Rosen LB, Freeman AF, Yang LM, Jutivorakool K, Olivier KN, Angkasekwinai $\mathrm{N}$, et al. Anti-GM-CSF autoantibodies in patients with cryptococcal meningitis. J Immunol. 2013;190(8):3959-66.

21. Kuo CY, Wang SY, Shih HP, Tu KH, Huang WC, Ding JY, et al. Disseminated cryptococcosis due to anti-granulocyte-macrophage colony-stimulating factor autoantibodies in the absence of pulmonary alveolar proteinosis. J Clin Immunol. 2017;37(2):143-52. 
22. Walsh TJ, Schlegel R, Moody MM, Costerton JW, Salcman M. Ventriculoatrial shunt infection due to Cryptococcus neoformans: an ultrastructural and quantitative microbiological study. Neurosurgery. 1986;18(3):373-5.

23. Martinez $L R$, Casadevall A. Specific antibody can prevent fungal biofilm formation and this effect correlates with protective efficacy. Infect Immun. 2005;73(10):6350-62.

24. Kidd FE, Hagen F, Tscharke RL, Huynh M, Bartlett KH, Fyfe M, et al. A rare genotype of Cryptococcus gattii caused the cryptococcosis outbreak on Vancouver Island (British Columbia, Canada). Proc Natl Acad Sci U S A. 2004; 101(49):17258-63.

25. Fraser JA, Giles SS, Wenink EC, Geunes-Boyer SG, Wright JR, Diezmann S. Same-sex mating and the origin of the Vancouver Island Cryptococcus gattii outbreak. Nature. 2005;437:1360-4.

26. Ngamskulrungroj P, Serena C, Gilgado F, Malik R, Meyer W. Global VGlla isolates are of comparable virulence to the major fatal Cryptococcus gattii Vancouver Island outbreak genotype. Clin Microbiol Infect. 2011;17:251-8.

27. Espinel-Ingroff A, Aller Al, Canton E, Castañón-Olivares LR, Chowdhary A, Cordoba S, et al. Cryptococcus neoformans-Cryptococcus gattii species complex: an international study of wild-type susceptibility endpoint distributions and epidemiological cutoff values for fluconazole, itraconazole, posaconazole, and voriconazole. Antimicrob Agents Chemother. 2012; 56(11):5898-906.

28. Thompson GR 3rd, Wiederhold NP, Fothergill AW, Vallor AC, Wickes BL, Patterson TF. Antifungal susceptibilities among different serotypes of Cryptococcus gattii and Cryptococcus neoformans. Antimicrob Agents Chemother. 2009;53(1):309-11.

29. Gutch RS, Nawange SR, Singh SM, Yadu R, Tiwari A, Gumasta R, et al. Antifungal susceptibility of clinical and environmental Cryptococcus neoformans and Cryptococcus gattii isolates in Jabalpur, a city of Madhya Pradesh in Central India. Braz J Microbiol. 2015;46(4):1125-33.

30. Santos AR, Gouveia LF, Taylor EL, Resende-Stoianoff MA, Pianetti GA, Cesar IC, et al. Dynamic interaction between fluconazole and amphotericin $B$ against Cryptococcus gattii. Antimicrob Agents Chemother. 2012;56(5):2553-8.

31. Larsen RA, Bauer M, Thomas AM, Graybill JR. Amphotericin B and fluconazole, a potent combination therapy for cryptococcal meningitis. Antimicrob Agents Chemother. 2004;48(3):985-91.

32. Pappas PG, Chetchotisakd P, Larsen RA, Manosuthi W, Morris M Anekthananon T. A phase II randomized trial of amphotericin B alone or combined with fluconazole in the treatment of HIV-associated cryptococcal meningitis. Clin Infect Dis. 2009;48(12):1775-83.

33. Molloy SF, Kanyama C, Heyderman RS, Loyse A, Kouanfack C, Chanda D. Antifungal combinations for treatment of cryptococcal meningitis in Africa. N Engl J Med. 2018;378(11):1004-17.

\section{Ready to submit your research? Choose BMC and benefit from:}

- fast, convenient online submission

- thorough peer review by experienced researchers in your field

- rapid publication on acceptance

- support for research data, including large and complex data types

- gold Open Access which fosters wider collaboration and increased citations - maximum visibility for your research: over $100 \mathrm{M}$ website views per year

At BMC, research is always in progress.

Learn more biomedcentral.com/submissions 